\title{
The role of ultrasonography (US), Doppler US artifacts and elastography in the detection of foreign bodies
}

\author{
Cemil Goya ${ }^{1}$, Alpaslan Yavuz ${ }^{2, ~}$, Cihad Hamidi ${ }^{1}$, Mehmet Guli Cetincakmak ${ }^{1}$, Salih Hattapoglu ${ }^{1}$, \\ Memik Teke ${ }^{1}$ \\ ${ }^{1}$ Radiology Department, School of Medical Science, Dicle University, Diyarbakir, Turkey \\ ${ }^{2}$ Radiology Department, School of Medical Science, Yuzuncu Yil University, Zeve Kampus, ErcisYolu, Van, Turkey
}

\section{Email address:}

cegoya1@yahoo.com (C. Goya), alp_yavuz@hotmail.com (A. Yavuz), cihad5@hotmail.com (C. Hamidi), mguli@mynet.com (M. G. Cetincakmak),drsalih80@hotmail.com (S. Hattapoğlu), memikteke@gmail.com (M. Teke)

\section{To cite this article:}

Cemil Goya, Alpaslan Yavuz, Cihad Hamidi, Mehmet Guli Cetincakmak, Salih Hattapoglu, Memik Teke. The Role of Ultrasonography (US), Doppler US Artifacts and Elastography in the Detection of Foreign Bodies. International Journal of Medical Imaging.

Vol. 2, No. 2, 2014, pp. 29-33. doi: 10.11648/j.ijmi.20140202.15

\begin{abstract}
Purpose: The aim of the study is to characterize the ultrasound and Doppler ultrasound artifact patterns of foreign bodies and to define the role of elastography in their detection. Material and method: Two in-vitro environments including a lamb leg and a lamb stomach coated with ultrasound gel, were prepared. Twenty-seven foreign bodies grouped as metallic, organic and inorganic were evaluated using the US, Doppler US and elastography imaging modalities. The Bmode US, Doppler US and spectral Doppler US images including their composed artifacts and the elastography findings were recorded. Results: US had detected all the foreign bodies located in both in-vitro environments. Clear and dirty shadowing was observed posteriorly to the foreign bodies and varying degrees of reverberation artifacts were present with 24 of the foreign bodies. Among the foreign bodies, 7 had twinkling artifacts, 23 had edge artifacts and 20 had spectral noise. Using power Doppler US, signals were received from the posterior aspect or the edge of 20 foreign bodies. The reverberation artifacts of the foreign bodies became more apparent in the elastography images. Conclusion: Knowledge of sonographic results along with ultrasound and Doppler ultrasound artifacts plays a key role in the detection and visualization of foreign bodies. Elastography further facilitates the diagnosis of the foreign bodies.
\end{abstract}

Keywords: Ultrasound, Foreign Body, Artifact, Elastography

\section{Introduction}

Foreign bodies (FB) typically enter the body as a result of incidents such as crashes, explosions, occupational accidents, fights, gunshot wounds, and falls. Another route of insertion is through the oral, nasal, or anal orifices in children and mentally retarded patients. ${ }^{1}$ Since FB that stay within the body can lead to infection or inflammation, they need to be located and removed. However, this is not always an easy task. While radio-opaque FB are visible with X-ray, those that are not radio-opaque are invisible to this technique. Sonography provided a sonic window is available to the FB and ultrasonography (US) can be used to locate organic and inorganic FB that are not readily visible on radiographs.

US is useful in locating non-opaque FB, especially those that are superficial, since it is a low-cost method that does not involve radioactivity. ${ }^{2-4}$ It has been reported that non- opaque FB can be located with B-mode US images. ${ }^{5-7}$ However, these studies have not reported the characterization of US and color Doppler US artifacts, nor have they reported the role of elastography in detecting FBs.

In this study, we aimed to investigate the US and Doppler US artifacts of FB, as well as the role of elastography in their detection. We hypothesized that the analysis of these artifacts would facilitate the detection of FB in environments where sonographic evaluation is confined by traumatic, edematous, heterogeneous, shallow soft tissues and abdominal intestinal structures.

\section{Materials and Methods}

Two in-vitro environments were prepared, including (I) a lamb leg and (II) a lamb stomach filled with ultrasound gel. The lamb leg and stomach originated from an animal slaughtered the previous day. FBs were inserted into the 
lamb leg and stomach through incisions. The FBs were individually placed in both environments and assessed using ultrasonography. The ACUSON S2000 ultrasound system (Siemens AG, Siemens Healthcare, Erlangen, Germany) $14 \mathrm{MHz}$ linear-and $4 \mathrm{MHz}$ convex probes was used for the ultrasonographic examinations. The ultrasonography was performed by a radiology specialist who has 10 years of experience at a university hospital. The approval of our institutional review board was obtained before the study.

The FBs were divided into 3 categories according to their composition (table 1). Metallic FBs had high atomic numbers and were visible with X-ray. Organic FBs were chosen from materials of plant origin, such as wood. Inorganic FBs were substances such as glass or plastic, which were not derived from a living material.

The gray-scale US, Doppler US, spectral Doppler US, and elastography findings were recorded. Based on the gray-scale US findings, the FBs were classified according to their contours as straight, round, ragged, or lobular echogenic materials. The shadowing posterior to the FB was classified as either clear or dirty acoustic shadowing. Reverberation artifacts and comet tail artifacts were evaluated separately. The degree of the reverberation artifact was visually evaluated as weak,,+++ , and +++ , with +++ indicating the highest reverberation artifact. Any twinkling artifact, edge artifact, or aliasing in the spectral window posterior to the object seen with Doppler US were recorded. To determine any differences in strength, the reverberation artifact seen with acoustic radiation force impulse (ARFI) elastography-Virtual touch imaging (VTI) was compared to the reverberation artifact seen with the Bmode images. Findings of ultrasound and color Doppler US artifacts were summarized in table 2 .

Table 1. Categories of foreign bodies.

\begin{tabular}{ll}
\hline Organic & pen, cardboard, olive, chickpea, chunk of wood, cotton \\
FB & wool, sponge, fresh wood \\
Inorganic & $\begin{array}{l}\text { marble, bead, glass shard, piece of a CD, button, zipper, } \\
\text { FB }\end{array}$ \\
with packaging tape \\
Metallic & $\begin{array}{l}\text { metal key, paper clip, copper ring, safety pin, sewing } \\
\text { needle, bullet, magnet, metal coin, battery, screw, staple }\end{array}$ \\
\hline
\end{tabular}

Table 2. Ultrasound and color Doppler ultrasound artifacts of foreign bodies.

\begin{tabular}{|c|c|c|c|c|c|c|c|}
\hline Foreign bodies & $\begin{array}{l}\text { Comet-tail } \\
\text { artifact }\end{array}$ & $\begin{array}{l}\text { Reverberation } \\
\text { artifact }\end{array}$ & $\begin{array}{l}\text { Twinkling } \\
\text { artifact }\end{array}$ & $\begin{array}{l}\text { Spectral } \\
\text { noise }\end{array}$ & $\begin{array}{l}\text { Edge } \\
\text { artifact }\end{array}$ & $\begin{array}{l}\text { Power } \\
\text { Doppler } \\
\text { US } \\
\end{array}$ & $\begin{array}{l}\text { Elastography } \\
\text { Reverberation } \\
\text { artifact }\end{array}$ \\
\hline Button & - & + & - & + & + & - & ++ \\
\hline Plastic caporlid & - & + & - & + & + & - & ++ \\
\hline Glass & - & + & - & + & + & + & ++ \\
\hline $\begin{array}{l}\text { Compact-disc } \\
\text { fragment }\end{array}$ & - & + & - & + & + & - & ++ \\
\hline Wood & - & + & - & + & + & + & ++ \\
\hline Cotton & - & + & - & - & + & + & + \\
\hline Sponge & - & + & - & + & + & & ++ \\
\hline Cardboard & - & + & - & - & + & + & ++ \\
\hline Pencil & - & + & - & - & & & ++ \\
\hline Olive & - & + & - & - & + & ++ & + \\
\hline Chickpea & - & - & - & - & + & + & + \\
\hline Glass bead & - & minimal & - & - & - & - & minimal \\
\hline Zipper & + & + & + & + & + & + & + \\
\hline Battery & + & + & - & + & + & + & +++ \\
\hline Coin & + & ++ & - & + & + & + & ++ \\
\hline Sewing needle & - & + & - & ++ & + & + & ++ \\
\hline Metal key & + & +++ & + & + & + & + & +++ \\
\hline Paperclip & + & + & + & + & + & + & +++ \\
\hline Bullet & - & + & + & + & + & + & ++++ \\
\hline Magnet & + & - & + & ++ & + & + & +++ \\
\hline Screw & + & + & ++++ & ++++ & - & + & +++ \\
\hline Copper ring & - & + & - & + & + & + & ++ \\
\hline Safety pin & + & + & + & + & + & + & + \\
\hline Gravel & - & + & - & + & - & - & ++ \\
\hline $\begin{array}{l}\text { Flour bag with parcel } \\
\text { tape }\end{array}$ & - & ++ & - & + & + & + & +++ \\
\hline
\end{tabular}

+: Positive, -: Negative

\section{Results}

All of the objects were observed in both in-vitro environments using US. Among the FBs, 15 were straight and linear, 8 were round, 1 was ragged and 3 were lobular in terms of echogenicity. Clear shadowing was observed behind $11 \mathrm{FBs}$, while dirty shadowing was observed behind 16 FBs. Only 8 FBs had comet tail artifacts. Three of the FBs had no reverberation artifacts, while 2 had weak, 19 had + degree, 2 had ++ degree, and 1 had +++ degree 
reverberation artifacts. The reverberation artifacts were observed to be stronger for metallic foreign bodies (Fig. 1).

The Doppler US revealed that only seven FBs had twinkling artifacts (Figs. 2 and 3), while 23 had edge artifacts (Fig. 4). Only aliasing aspect of the artifact (without the accompaniment of rapidly changing red and blue colors) was observed during the imaging of implied seven FBs in the spectral mode of color Doppler US. Twenty FBs caused spectral signal (Fig. 5). Power Doppler US identified signals that were received from the posterior or the edge of $20 \mathrm{FBs}$.

Elastography did not reveal any distinguishing images of the FBs. However, the reverberation artifacts of all of the FBs became more apparent with elastography than they did in the gray-scale images (Fig. 6). No quantitative values were recorded from the majority of the FBs, although 3 were recorded using the acoustic radiation force impulse (ARFI) cursor.



Figure 1. Remarkable reverberation artifact related to bullet in jelly were revealed.
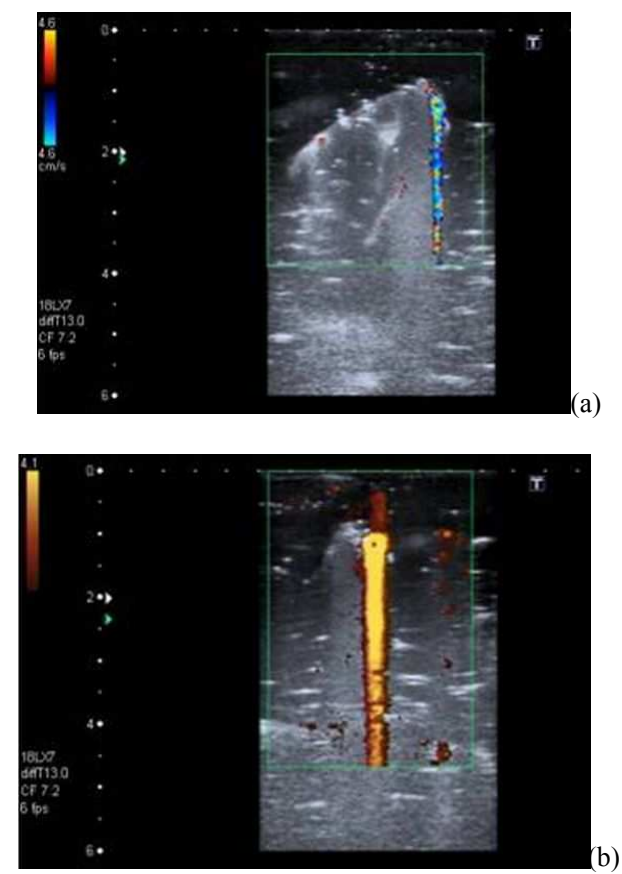

Figure 2. "Twinkling" artifact was detected at irregular borders of bullet by (a) color and (b) power Doppler ultrasound imaging.

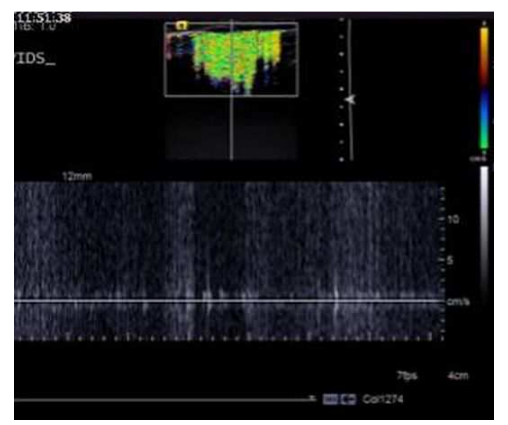

Figure 3. Sonographic examination of screw. "Twinkling” artifact in color Doppler ultrasound imaging and spectral "aliasing" artifact in spectral Doppler ultrasoun imaging.


Figure 4. Sonographic examination of olive. Increased echogenity in (a)BMod ultrasound due to fatty components and "edge" artifact in (b) color Doppler and (c) power Doppler ultrasound were determined.








Figure 5. Spectral signal related to (a) glass and (b) magnet pieces was determined by spectral Doppler ultrasound imaging.
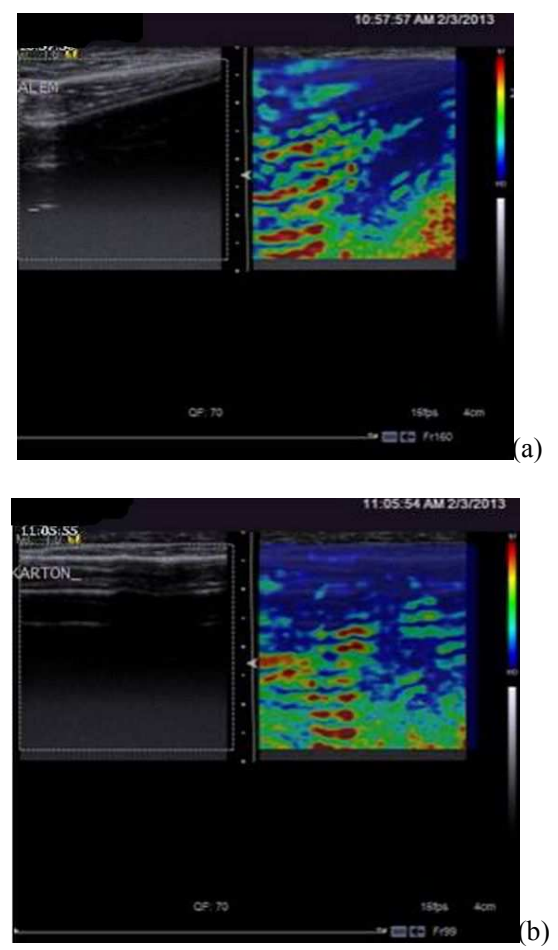

Figure 6. Right sided linear echogenity and posterior blank acoustic shadowing related to (a) pencil and (b) carton paper; reverberation artifact which was weak in B-Mod is visually remarkable in elastographic examination.

The echogenic line shadowing and the reverberation artifacts were weaker in the organic and inorganic objects than in the metallic objects with high atomic numbers. In both in -vitro environments, similar artifacts were observed using all 3 methods, although the reverberation artifacts of all of the foreign bodies were stronger in the second environment (lamb stomach).

\section{Discussion}

This study confirmed that the various artifacts of FBs can be visualized with US, color Doppler US, and elastography, and that FBs can be detected via these artifacts. In a review of current literature, we found that no such study has been previously conducted.

Ultrasonography evaluates the sonographic echo that returns to the transducer after a single reflection, and calculates its depth based on the time it takes to return. In the case of two parallel surfaces with high reflectivity, echoes produced from the primary ultrasound signal may be reflected back and forth before being read by the transducer. Since it takes more time for the consecutive echoes to return to the transducer, the processor of the ultrasonography device may mistakenly place the delayed echoes further away than they actually are. This appears as multiple linear reflections at equal distances, which are defined as reverberation artifacts.

Comet tail artifacts are also a form of reflection in which two reflective intermediate surfaces and the related consecutive echoes are located very close to each other. The consecutive echoes may be so close on the screen that the individual echoes cannot be distinguished from one another. In addition, the amplitude of the waves is reduced. The resulting image is an artifact arising from the reflection principle, and is shaped like a triangle that gradually sharpens towards the top.

Twinkling artifacts were first described by Rahmouni et al. in $1996 .{ }^{8}$ The main features of these particular artifacts are rapidly changing red and blue Doppler signals that are seen behind certain stationary objects, which mimics the similar appearance properties of movement that is mostly observed with with power Doppler US. ${ }^{8,9}$ Twinkling artifact's classic aliasing signal pattern in the spectral window have previously been used in the verification of stones in clinical practice. Howver; in our study, only aliasing (without the accompaniment of rapidly changing red and blue colors) was observed during the imaging of FBs in the spectral mode of color Doppler US. Aliasing is related to the window level selection and the device parameters, and the presence of such artifact may be considered to be a positive indicator for the existence of twinkling artifact. This spectral noise artifact is formed in a limited region behind the adjacent region of the object interface, frequently behind the very object that caused the artifact to occur. The generated wave is a thin and heterogeneous broad-band signal when evaluated with spectral Doppler sonography. While bodies with irregular surfaces, such as screws, cause exaggerated reverberation, twinkling, and spectral aliasing; bodies with rugged surfaces are more clearly defined. Metallic FBs with smooth surfaces do not cause any twinkling artifact. However, they cause more apparent reverberations and spectral aliasing patterns than organic and inorganic materials.

In our study, we revealed that the accompanied artifacts' strength can be depend on the structural component of the object that; the objects composed of organic and inorganic materials other than metal has a weaker echogenic line shadowing and the reverberation artifacts when compared with metallic objects by a higher atomic numbered compositions. Metal objects have more evident features in artifact based sonographic imaging; thus their diagnosis could successfully be performed by aforementioned sonographic examination modalities. 
Edge artifacts are associated with strong specular reflectors, and are observed as smooth colors around calcified structures such as the gall bladder or the cortical bone. In the same way, the Doppler spectrum demonstrates a straight-line noise pattern with no pulsation. Edge artifacts are more frequently observed in power Doppler US than in color Doppler US. ${ }^{8}$ In our study, edge artifacts accompanied 23 of the FBs. In our experience, edge artifacts are frequently observed with FBs in in-vitro studies.

Elastography aims to exploit differences in elasticity to identify new tissues. ${ }^{10-13}$ A new method used for the quantification of tissue elasticity is the Acoustic Radiation Force Impulse (ARFI). This elastometric technique is incorporated within a conventional ultrasound system and permits the non-invasive quantification of tissue elasticity in real-time during a B-mode US examination. ${ }^{11}$ In our study, elastographic US imaging of the FBs was resulted with an augmentation of the reverberation artifacts but no distinguishing images of the FBs could be obtained. Additionally, the elastometric quantification of the visual changes due to FB seems to be discouraging even to highlight a definite diagnosis or contribute the differential diagnosis. However, recent technologic developments involving the new era of sonographic elastographic examinations have the potential to overcome such issues at a near future.

The greatest limitation of our study is the in-vitro design and we did not evaluate FBs as a double-blind.

We conclude that sonographic results along with US and Doppler US artifacts play a key role in the detection and visualization of foreign bodies. Elastography is most useful in increasing the posterior reverberation of the foreign bodies.

\section{References}

[1] Gunaydin M, Tander B, Bicakcı U, Guzel A, Rizalar R, Ariturk E, Bernay F. Characteristics of bean aspiration in children. J ClinExpInvest 2012; 3:18-21.
[2] Shiels WE, Babcock DS, Wilson JL, Burch RA. Localization and guided removal of soft-tissue foreign bodies with sonography. AJR Am J Roentgenol 1990 Dec;155(6):1277-81.

[3] Donaldson JS. Radiographic imaging of foreign bodies in the hand. HandClin1991 Feb;7(1):125-34.

[4] Horton LK, Jacobson JA, Powell A, Fessell DP, HayesCW. Sonography and radiography of soft-tissue foreign bodies. AJR Am J Roentgenol 2001 May;176(5):1155-9.

[5] Jacobson JA, Powell A, Craig JG, Bouffard JA, vanHolsbeeck MT. Wooden foreign bodies in soft tissue detection: detection at US. Radiology 1998 Jan;206(1):45-8.

[6] Brau PW, Mahoney JL, Campbell JP. Sensitivity and specificity of ultrasound in the detection of foreign bodies in the hand. J HandSurgAm1995 Jul;20(4):661-6.

[7] Gilbert FJ, Campbell RS, Bayliss AP. The role of ultrasound in the detection of non-radiopaque foreign bodies. ClinRadio 1990 Feb;41(2):109-12.

[8] Rahmouni A, Bargoin R, Herment A, Bargoin N, Vasile N. Color Doppler twinkling artifact in hyperechoic regions. Radiology 1996 Apr;199(1):269-71.

[9] Lee JL, Kim SH, Cho JY, Han D. Color and power Doppler twinkling artifacts from urinary stones: clinical observations and phantom studies. AJR Am J Roentgenol 2001 Jun;176(6):1441-5.

[10] Fleury Ede F, Fleury JC, Piato S, Roveda D Jr. New elastographic classification of breast lesions during and after compression.DiagnIntervRadiol2009 Jun;15(2):96-103.

[11] Hanquinet S, Courvoisier D, Kanavaki A, Dhouib A, Anooshiravani M. Acoustic radiation force impulse imaging-normal values of liver stiffness in healthy children. PediatrRadiol 2013 Mar;43(5):539-44.

[12] Onur MR, Poyraz AK, Ucak EE, Bozgeyik Z, Özercan IH, Ogur E. Semiquantitative strain elastography of liver masses. J Ultrasound Med 2012; 31:1061-67.

[13] Calvete AC, Rodríguez JM, de Dios Berná-Mestre J, Ríos A, Abellán-Rivero D, Reus M. Interobserver agreement for thyroid elastography: value of the quality factor. J Ultrasound Med 2013; 32:495-504. 